Rev. Ter. Ocup. Univ. São Paulo, v. 17, n. 2, p. i, maio/ago., 2006.

\title{
Editorial
}

\section{A Terapia Ocupacional da USP na Pós Graduação}

\author{
Selma Lancman, Elisabete Ferreira Mângia, Marta Carvalho de Almeida
}

É com grande orgulho que apresentamos o Programa de Pós-graduação em Ciências da Reabilitação, criado em 2005, no Departamento de Fisioterapia, Fonoaudiologia e Terapia Ocupacional da FMUSP. Trata-se de um curso de mestrado e doutorado com duas áreas de concentração: Comunicação Humana e Movimento, Postura e Ação Humana.

A criação desta pós-graduação, que vêm se somar ao programa de Ciências da Reabilitação já existente na UFMG, nos leva a refletir sobre a importância para a Terapia Ocupacional da criação de programas desta natureza na atual fase de desenvolvimento da profissão no país.

Os profissionais que acompanharam e acompanham o processo enfrentado para entrarmos no sistema de pós-graduação conhecem as dificuldades vivenciadas e o fato de precisarmos construir caminhos sem contarmos com nenhuma estrutura prévia já consolidada que nos apoiasse ou subsidiasse. Enumeramos algumas delas: os critérios e as regras de credenciamento para novos cursos e novos orientadores, que não levam em conta a realidade de grupos emergentes; a dificuldade de publicar artigos em revistas de impacto, visto que, a maioria dos periódicos da área de Terapia Ocupacional no Brasil e no mundo não possui o nível de indexação exigido pela CAPES; a falta de linhas de pesquisa definidas que agreguem um número significativo de pesquisadores; a dispersão de doutores em diversas escolas; entre outros. Soma-se a isso, a característica interdisciplinar da área, que muitas vezes nos aproxima mais das ciências humanas e de suas metodologias de pesquisa do que das ciências biológicas, hegemônicas na área da saúde.

Atualmente, a pós-graduação stricto sensu é reconhecida como o principal espaço de formação de pesquisadores e produção de conhecimento. Se, de um lado, é verdade que já constituímos uma massa critica de doutores formados em áreas afins, também é fato que estes doutores muitas vezes encontram-se órfãos e isolados. Esta dispersão dificulta a consolidação de grupos e linhas de pesquisa que permitam desenvolver e consolidar o conhecimento adquirido e limitam o diálogo científico necessário para se constituir "escolas de terapia ocupacional", entendidas aqui como grupos organizados que trabalhem em áreas afins e que possam, ao longo dos anos, dar seguimento, fazer avançar e consolidar experiências, idéias, teorias e métodos.

A expansão recente dos cursos de graduação em Terapia Ocupacional, a necessidade de somarmos esforços para garantir a qualidade dos mesmos, de melhorar e expandir a complexa assistência à população atendida, de desenvolver e fortalecer o mercado de trabalho, de assegurar o reconhecimento público da profissão evidenciam ainda mais a importância da produção cientifica que alimente esta expansão e rompa o circulo vicioso implicado nos seguintes aspectos: a falta de reconhecimento profissional; a perda de campo de trabalho para outros profissionais menos qualificados; a qualificação em outras áreas e consequiente perda de alunos e de produção cientifica para outros campos; as dificuldades de aglutinação e de ressonância da produção cientifica na terapia ocupacional; os limites na reprodução do conhecimento acumulado em práticas de ensino, clínico/assistenciais e em projetos de intervenção; a dificuldade de se criar uma prática de pesquisa que se inicie na graduação, mas que, sobretudo, ofereça ao aluno oportunidades de continuidade de desenvolvimento após a graduação.

A situação atual também resulta na reduzida demanda de projetos em agências de fomento à pesquisa, o que acaba limitando o aporte de financiamento para a área como um todo. Um exemplo disto foi a ameaça recentemente vivenciada de deixarmos de ser uma área e virarmos uma especialidade dentro da CAPES e do CNPq.

É claro que a pós-graduação é somente um dos caminhos possíveis para o desenvolvimento da profissão e que é necessário muito mais. Mas não restam dúvidas de que a consolidação da Terapia Ocupacional no sistema de pósgraduação do país é um importante passo nessa direção.

Editoras da Revista de Terapia Ocupacional da USP.

Docentes do Curso de Graduação em Terapia Ocupacional da FMUSP. 